\title{
HCV Antibody Signal to HCV Antibody Cutoff Ratio Measurement
}

National Cancer Institute

\section{Source}

National Cancer Institute. HCV Antibody Signal to HCV Antibody Cutoff Ratio

Measurement. NCI Thesaurus. Code C139086.

The determination of the ratio of the Hepatitis C virus antibody signal in a biological specimen to Hepatitis C virus positive internal control. The measurement may be expressed as a ratio or percentage. 